\title{
Potencial genético da população de milho UFV 7 para o melhoramento em Minas Gerais
}

\author{
Genetic potential of maize population UFV 7 for breeding in Minas Gerais \\ Joyce de Souza Faluba ${ }^{\mathrm{I}}$ Glauco Vieira Miranda ${ }^{\mathrm{I}^{*}}$ Rodrigo Oliveira DeLima $^{\mathrm{I}}$ \\ Leandro Vagno de Souza ${ }^{I I}$ Enoch Assis Debem ${ }^{I}$ Ana Maria Cruz e Oliveira ${ }^{I}$
}

\section{RESUMO}

Neste trabalho, objetivou-se avaliar o potencial genético da população de milho UFV 7 para o melhoramento em Minas Gerais. Foram instalados três experimentos com a população de milho UFV 7, em três regiões de Minas Gerais, na safra 2006/2007. Houve interação genótipos x ambientes para todos os caracteres. Foi verificada variabilidade genética para produtividade de grãos, altura de plantas e altura de espigas na população de milho UFV 7, nas três regiões. $\mathrm{Na}$ região Sudeste, a população de milho UFV 7 apresentou as maiores estimativas de parâmetros genéticos. A população UFV 7 apresentou alta produtividade de grãos, $9112 \mathrm{~kg} \mathrm{ha}^{-1}$, no Sudeste, média produtividade, $6510 \mathrm{~kg} \mathrm{ha}^{-1}$, no Oeste, e baixa, $4572 \mathrm{~kg} \mathrm{ha}^{-1}$, na região Central. As estimativas de herdabilidade e $\mathrm{CVg} / \mathrm{CVe}$, para produtividade, foram superiores a $60 \%$ e 1,00, respectivamente. A produtividade de grãos teve correlação genética significativa e positiva com a altura de planta e altura de espiga, na região Oeste e na Central, e com a prolificidade na região Central e região Sudeste. Conclui-se que a população de milho UFV 7 apresenta potencial para extração de linhagens na região Central; potencial para uso imediato na região Sudeste e para novos ciclos de seleção na região Oeste de Minas Gerais, e a seleção para PG aumenta indiretamente a altura de planta e altura de espiga, nas regiões Oeste e Central.

Palavras-chave: parâmetros genéticos, correlação, seleção.

\section{ABSTRACT}

The objective was to assess the genetic potential of maize population UFV 7 for breeding in Minas Gerais, Brazil. Three experiments were installed with the maize population UFV 7 in the three regions of Minas Gerais, in the harvest of 2006/2007. There was genotype $x$ environment interaction for all characters. It was observed genetic variability for grain yield, plant height and ear height in maize population UFV 7 , in the three regions. The Southeast region was where the maize population UFV 7 had the highest parameters. The population UFV 7 presented high grain yield, $9112 \mathrm{~kg} \mathrm{ha}^{-1}$ in the Southeast, average grain yield, $6510 \mathrm{~kg} \mathrm{ha}^{-1}$ in the West and low, $4572 \mathrm{~kg}$ $\mathrm{ha}^{-1}$ in the Central Region. Heritability estimate and CVg / CVe for grain yield were higher than $60 \%$ and 1.00 , respectively. Grain yield had significant and positive genetic correlation with plant height and ear height, in Western and Central, and the prolificacy in Central and Southeast. For maize population UFV 7 it was conclude that it has potential for extraction of lines in the Central Region; it has the potential for immediate use in the Southeast and for new cycles selection in the Western Region of Minas Gerais. The selection for PG provides an indirect increase in plant height and ear height, in the West and Central.

Key words: genetic parameters, correlation, selection.

\section{INTRODUÇÃO}

Apesar de destaque na produção nacional de milho, com uma média de produtividade de $5113 \mathrm{~kg}$ $\mathrm{ha}^{-1}$, Minas Gerais apresenta contrastes relevantes quanto à produtividade de grãos desse cereal. Enquanto a produtividade de milho no Triângulo Mineiro é de $6299 \mathrm{~kg} \mathrm{ha}^{-1}$, na região Central é de 3 $999 \mathrm{~kg} \mathrm{ha}^{-1}$, na Região Sudeste é de $3265 \mathrm{~kg} \mathrm{ha}^{-1}$, no Norte de Minas é de apenas $1898 \mathrm{~kg} \mathrm{ha}^{-1}$ (IBGE, 2009). Entre os fatores responsáveis pela grande variação na

'Departamento de Fitotecnia, Universidade Federal de Viçosa (UFV), 36570-000, Viçosa, MG, Brasil. E-mail: glaucovmiranda@ufv.br.

*Autor para correspondência.

"Dow Agrosciences Indústria Ltda, Ribeirão Preto, SP, Brasil. 
produtividade de milho mineira estão as características edafoclimáticas específicas de cada região, as disparidades sociais e os diferentes níveis tecnológicos adotados pelos produtores e, ainda, o tipo de agricultura de cada região - familiar ou empresarial. Assim, os programas de melhoramento de milho devem buscar atender as particularidades dos ambientes e agricultores, com a finalidade de obter materiais genéticos adaptados e produtivos.

O desenvolvimento de cultivares de milho deve capitalizar a interação genótipos x ambientes, principalmente para as várias condições edafoclimáticas e sociais dos sistemas de produção (MIRANDA et al., 2009; SOUZA et al., 2009a). Desse modo, a interação genótipos $\mathrm{x}$ ambientes poder ser maximizada com a seleção de genótipos específicos para cada região (DEITOS et al., 2006).

SOUZA et al. (2009a) avaliaram uma população de milho crioulo resgatada em Barbacena, no Sul e no Sudeste de Minas Gerais e no Norte do Rio de Janeiro. Os autores constataram que, para produtividade de grãos, no Norte do Rio de Janeiro e no Sudeste de Minas Gerais, 65,83 e 57,9\%, respectivamente, da variabilidade manifestada na população foi de natureza genética. Assim, ganhos para aumentar a produtividade de grãos serão obtidos caso alguma técnica seletiva seja aplicada nessa população de milho. Entretanto, no Sul de Minas Gerais, a variabilidade manifestada na população foi unicamente de natureza ambiental, ou seja, não são esperados ganhos para produtividade de grãos com uso de algum método de melhoramento para essa população nessa região.

SILVA et al. (2008) avaliaram o potencial das populações de milho UFVM 100 e UFVM 200 para produtividade de grãos, no Noroeste de Minas Gerais, em alto e baixo nitrogênio $(\mathrm{N})$. A população de milho UFVM 100 manifestou variabilidade genética para o caráter em alto e baixo N, enquanto a UFVM 200 não apresentou variabilidade genética em ambos os níveis de N. A população de milho UFVM 200 apresentou estimativa de variância ambiental superior a UFVM 100, ou seja, houve uma expressiva manifestação de variação ambiental de forma não haver manifestação de variabilidade genética pela população de milho UFVM 200.

A estimativa de parâmetros genéticos é muito importante no melhoramento de plantas porque permite identificar a natureza da ação dos genes envolvidos no controle dos caracteres quantitativos e avaliar a eficiência de diferentes estratégias de melhoramento para a obtenção de ganhos genéticos e manutenção da base genética adequada nas populações. Desse modo, estimativas de médias, variância genética, herdabildidade e correlação entre os caracteres dos componentes primários e secundários de produção possibilitam conhecer o potencial das populações para o melhoramento. Além disso, a correlação entre produtividade de grãos e caracteres secundários de produção em populações de milho é muito influenciada pelo ambiente (SOUZA et al., 2009b).

O método de melhoramento de seleção recorrente intrapopulacional entre progênies de meiosirmãos é muito usado em melhoramento de populações de milho de polinização aberta (CARVALHO et al., 2003; CARVALHO \& SOUZA, 2007; SOUZA et al., 2009a). Ele é simples, rápido e eficiente na avaliação de potencial de populações de milho (BORÉM \& MIRANDA, 2009). Desse modo, neste trabalho, objetivou-se avaliar o potencial genético da população de milho UFV 7 para o melhoramento em Minas Gerais.

\section{MATERIAL E MÉTODOS}

Os experimentos foram conduzidos em três locais de Minas Gerais: na Região Sudeste (Zona da Mata), na Estação Experimental de Coimbra, à latitude $20^{\circ} 51^{\prime} 24^{\prime \prime}$ sul e à longitude $42^{\circ} 48^{\prime} 10^{\prime \prime}$ oeste, estando à altitude de 720m; na Região Oeste (Cerrado), na Central de Experimentação, Pesquisa e Extensão do Triângulo Mineiro (CEPET), em Capinópolis, à latitude 1840'55" sul e à longitude $49^{\circ} 34^{\prime} 11^{\prime \prime}$ oeste, à altitude de 564m; e na Região Central (Transição), em Florestal, à latitude $19^{\circ} 53^{\prime} 22^{\prime \prime}$ sul e à longitude $44^{\circ} 25^{\prime} 57^{\prime}$ ' oeste, à altitude de $776 \mathrm{~m}$.

A população de milho UFV 7 foi originada de cruzamentos entre híbridos de milho comercias e produtivos na região Sudeste de Minas Gerais. Ela apresenta grãos do tipo duro e alaranjado. Essa população foi obtida após três ciclos de acasalamento ao acaso em campos isolados. Foram selecionadas 100 progênies de meios-irmãos maternos da população de milho-base para serem avaliados. O critério de seleção das progênies foi o empalhamento adequado, o tamanho de espigas, o tipo de grão duro e a ausência de pragas e doenças.

As 100 progênies de meios-irmãos foram avaliadas na safra 2006/2007. Utilizou-se o delineamento experimental látice $10 \times 10$, com duas repetições. A parcela constou de uma fileira de 4,0m de comprimento, espaçada de $0,9 \mathrm{~m}$. Aos 21 dias após a emergência das plântulas, foi realizado o desbaste, de modo a ter uma população de 55555 plantas ha-1.

A adubação de plantio foi de $450 \mathrm{~kg} \mathrm{ha}^{-1} \mathrm{de}$ N-P-K, formulação 8-28-16, em Coimbra, e 300 $\mathrm{kg} \mathrm{ha}^{-1}$, 
em Capinópolis e Florestal. Em todas as regiões, a adubação de cobertura foi de $92 \mathrm{~kg}$ de $\mathrm{N} \mathrm{ha}^{-1}$, na forma de ureia. A ureia foi aplicada no solo junto às plantas, quando estas apresentavam seis folhas completamente desenvolvidas.

Os caracteres avaliados foram: produtividade de grãos $\left(\mathrm{kg} \mathrm{ha}^{-1}\right)$, alturas de planta $(\mathrm{cm})$ e espiga $(\mathrm{cm})$ e prolificidade (número médio de espigas por planta). Realizou-se, inicialmente, a análise de variância por região, segundo o esquema em látice e, posteriormente, procedeu-se à análise de variância conjunta a partir das médias ajustadas dos tratamentos. Obedeceu-se ao critério de homogeneidade dos quadrados médios residuais.

Nas três regiões, para a população de milho UFV 7, foram estimados os coeficientes de correlação fenotípica $\left(r_{p}\right)$, genotípica $\left(r_{g}\right)$ e de ambiente $\left(r_{a}\right)$ entre os pares de caracteres (CRUZ et al., 2004). A significância dos coeficientes de correlação foi avaliada pelo teste $\mathrm{t}$, a 5 e $1 \%$ de probabilidade. Além disso, foram estimadas a relação entre os coeficientes de variação genética e coeficiente de variação experimental $(\mathrm{CVg} / \mathrm{CVe})$ e a herdabilidade no sentido restrito, com base na média de progênies $\left(h^{2}\right)$ para todos os caracteres avaliados na população de milho UFV 7.

\section{RESULTADOS E DISCUSSÃO}

Foi constatada diferença significativa $(\mathrm{P} \leq 0,01)$ entre as progênies de meios-irmãos de milho para quase todos os caracteres, com exceção do caráter prolificidade na região Oeste. Consequentemente, há variabilidade genética para produtividade de grãos, altura de plantas e altura de espigas na população de milho UFV 7, nas três condições edafoclimáticas. Assim, é possível que ganhos sejam obtidos a partir do melhoramento nessa população, nas diversas condições edafoclimáticas de Minas Gerais.

Quando se avalia um experimento em apenas um local, a variância genética está inflacionada pela interação genótipos $\mathrm{x}$ ambientes. $\mathrm{Na}$ análise conjunta, o componente da interação pode ser isolado (RAMALHO et al., 2005). As análises de variâncias conjuntas confirmaram a alta variabilidade genética da população de milho UFV 7 para todos os caracteres. A fonte de variação, devido aos ambientes (A) e da interação genótipos $\mathrm{x}$ ambientes $(\mathrm{G} \times \mathrm{A})$, foram significativas $(\mathrm{P} \leq 0,01)$ para todos os caracteres. Isso sugere que os ambientes se comportaram diferentemente quanto aos valores médios das progênies para os diversos caracteres. Além disso, as progênies apresentaram comportamento diferenciado em virtude das variações ambientais.
A estimativa da variância da interação genótipos $\mathrm{x}$ ambientes $\left(\sigma_{\mathrm{ga}}^{2}\right)$ para produtividade de grãos correspondeu a 72,2 e $70,9 \%$ da estimativa da variância genética $\left(\sigma_{\mathrm{g}}^{2}\right)$ nas regiões Oeste e Sudeste, respectivamente. Para esse caráter, a $\sigma_{\mathrm{ga}}^{2}$ foi superior a $\sigma_{\mathrm{g}}^{2}$ observada na região Central. Foi verificada alta magnitude do $\sigma_{\text {ga }}^{2}$, como observado em outros trabalhos realizados com milho (CARVALHO et al., 2003 e 2007; CARDOSO et al., 2003; MIRANDA et al. 2008; MIRANDA et al. 2009). A $\sigma_{\mathrm{g}}^{2}$ foi de alta magnitude, porém $46,1 \%$ inferior a $\sigma_{\text {ga }}^{2}$ com base na média das três regiões (Tabela 1). As estimativas da variância genéticas obtidas em populações de milho no Brasil (PACHECO et al., 1998; CARVALHO et al., 2003, 2007; CARDOSO et al., 2003), para condições semelhantes a essa, variaram entre $103700\left(\mathrm{~kg} \mathrm{ha}^{-1}\right)^{2}$ e $248750\left(\mathrm{~kg} \mathrm{ha}^{-1}\right)^{2}$, inferiores às encontradas na população de milho UFV 7, para essas condições edafoclimáticas.

A relação entre coeficiente de variação genética, coeficiente de variação ambiental $(\mathrm{CVg} / \mathrm{CVe})$ e coeficiente de herdabilidade $\left(\mathrm{h}^{2}\right)$ constituem medidas de influência do ambiente sobre a expressão dos fenótipos. Para produtividade de grãos, a estimativa da relação $\mathrm{CVg} / \mathrm{CVe}$ e da herdabilidade foi de $0,64 \mathrm{e}$ $47,04 \%$, para média das três regiões (Tabela 1 ). Isso mostra situação pouco favorável à seleção, uma vez que a situação torna-se favorável quando a relação $\mathrm{CVg} / \mathrm{CVe}$ atinge valores próximos ou superiores a 1,00. Apesar disso, esses valores são superiores aos encontrados em uma população de milho crioulo para produtividade de grãos (SOUZA et al., 2009a) e na população BR 5028 para peso de espigas (CARVALHO et al., 2007). Entretanto, inferiores aos obtidos na população de milho CPATC-3 para peso de espigas, avaliado em dois locais de Sergipe (CARVALHO et al., 2003). Todas as comparações foram realizadas considerando apenas o primeiro ciclo de seleção de cada população e estimativas provenientes de análises com base na média de locais. De fato, estimativas de $\mathrm{CVg} / \mathrm{CVe}$, com base na média de dois ou mais locais, normalmente, apresentaram-se inferiores às estimativas com base em apenas um local, no qual é mais comum encontrar valores bem próximos ou superiores a 1,00.

No caso em que se deseja maximizar os ganhos para uma série de ambientes, o apropriado é que estes sejam estimados com uso do componente de variância genética da análise conjunta (CRUZ et al., 2004). No entanto, neste trabalho, pretende-se selecionar progênies que venham a formar populações com adaptações específicas para as regiões avaliadas, de modo capitalizar a interação genótipos x ambientes. Assim, foram estimados os parâmetros genéticos na população de milho UFV 7 para todos os caracteres em cada uma das três regiões. 
Tabela 1 - Estimativas das variâncias genética $\left(\sigma_{\mathrm{g}}^{2}\right)$, aditiva $\left(\sigma_{\mathrm{a}}^{2}\right)$, interação genótipos x ambientes $\left(\sigma_{\text {ga }}^{2}\right)$, ambiental $\left(\sigma^{2}\right)$ e fenotípica $\left(\sigma_{\mathrm{p}}^{2}\right)$, $\mathrm{CVg} / \mathrm{CVe}$ e herdabilidades no sentido restrito $\left(\mathrm{h}^{2}\right)$ relativos aos caracteres da população de milho UFV 7 , na média das três regiões.

\begin{tabular}{llccc}
\hline Parâmetros & Produtividade de grãos $\left(\mathrm{kg} \mathrm{ha}^{-1}\right)$ & Altura de planta $(\mathrm{cm})$ & Altura de espiga $(\mathrm{cm})$ \\
\hline Média & 6731 & 188,12 & 97,07 & 7 \\
$\sigma_{\mathrm{g}}^{2}$ & 480503 & 9 & 29 & 0,03 \\
$\sigma_{\mathrm{a}}^{2}$ & 1922014 & 37 & 33 & 0,0156 \\
$\sigma_{\text {ga }}^{2}$ & 1042057 & 68 & 72 & 0,0021 \\
$\sigma^{2}$ & 1161113 & 113 & 30 & 0,0291 \\
$\sigma_{\mathrm{p}}^{2}$ & 1021375 & 51 & 0,32 & 0,0094 \\
$\mathrm{CVg} / \mathrm{CVe}$ & 0,64 & 0,29 & 24,01 & 0,37 \\
$h^{2}(\%)$ & 47,04 & 18,39 & 41,49 \\
\hline
\end{tabular}

Na região Sudeste, a população de milho UFV 7 apresentou as maiores estimativas de parâmetros para quase todos os caracteres, com destaque para média de produtividade de grãos (Tabela 2). Esta na região Sudeste foi de 40 e $100 \%$ superior às médias apresentadas na região Oeste e Central, respectivamente. Na região Central, a população de milho UFV 7 manifestou as menores estimativas de parâmetros genéticos. Isso mostra a menor adaptação da população de milho UFV 7 à essa região. Como essa população de milho foi desenvolvida na região Sudeste de Minas Gerais, já era esperado que ela apresentasse maior adaptação a essa região.

A produtividade de grãos de milho é o caráter de maior interesse para os agricultores. Portanto, o aumento desse caráter é sempre prioritário em todo programa de melhoramento, e o uso da seleção recorrente é um método de melhoramento eficiente quando se pretende aumentar a produtividade de grãos de determinada população. A relação $\mathrm{CVg} / \mathrm{CVe}$ e a

Tabela 2 - Estimativas das variâncias genética $\left(\sigma_{\mathrm{g}}^{2}\right)$, aditiva $\left(\sigma_{\mathrm{a}}^{2}\right)$, ambiental $\left(\sigma^{2}\right)$ e fenotípica $\left(\sigma_{\mathrm{p}}^{2}\right)$, relação $\mathrm{CVg} / \mathrm{CVe}$ e herdabilidade no sentido restrito com base na média de progênie $\left(h^{2}\right)$ para os caracteres na população de milho UFV 7, nas três regiões de Minas Gerais.

\begin{tabular}{|c|c|c|c|c|}
\hline & Produtividade de grãos $\left(\mathrm{kg} \mathrm{ha}^{-1}\right)$ & Altura de planta $(\mathrm{cm})$ & Altura de espiga $(\mathrm{cm})$ & Prolificidade \\
\hline Média & 6510 & 193,08 & 97,67 & 1,00 \\
\hline$\sigma_{g}^{2}$ & 1794734 & 68 & 32 & 0,0026 \\
\hline$\sigma_{\mathrm{a}}^{2^{5}}$ & 7178934 & 273 & 126 & 0,0104 \\
\hline$\sigma^{2}$ & 650288 & 62 & 44 & 0,0161 \\
\hline$\sigma_{p}^{2}$ & 2445021 & 131 & 75 & 0,0187 \\
\hline $\mathrm{CVg} / \mathrm{CVe}$ & 1,17 & 0,74 & 0,60 & 0,28 \\
\hline$h^{2}(\%)$ & 73,40 & 52,31 & 41,86 & 13,87 \\
\hline Média & 9112 & $\begin{array}{c}\text { gião Sudeste----- } \\
218\end{array}$ & 116 & 1,20 \\
\hline$\sigma_{g}^{2}$ & 1772836 & 78 & 50 & 0,0065 \\
\hline$\sigma_{a}^{2}$ & 7091345 & 311 & 200 & 0,0260 \\
\hline$\sigma^{2}$ & 639052 & 53 & 42 & 0,0153 \\
\hline$\sigma_{p}^{2}$ & 2411888 & 131 & 92 & 0,0218 \\
\hline $\mathrm{CVg} / \mathrm{CVe}$ & 1,18 & 0,86 & 0,77 & 0,46 \\
\hline$h^{2}(\%)$ & 73,50 & 59,45 & 54,12 & 29,82 \\
\hline Média & 4572 & $\begin{array}{c}\text { giao central-- } \\
153\end{array}$ & 77 & 0,89 \\
\hline$\sigma_{g}^{2}$ & 1000111 & 87 & 39 & 0,0087 \\
\hline$\sigma_{\mathrm{a}}^{2^{8}}$ & 4000445 & 347 & 157 & 0,0348 \\
\hline$\sigma^{2}$ & 452331 & 54 & 22 & 0,0124 \\
\hline$\sigma_{p}^{2}$ & 1452442 & 141 & 62 & 0,021 \\
\hline $\mathrm{CVg} / \mathrm{CVe}$ & 1,05 & 0,90 & 0,94 & 0,59 \\
\hline$h^{2}(\%)$ & 68,86 & 61,57 & 63,70 & 41,24 \\
\hline
\end{tabular}


herdabilidade são parâmetros que medem a confiabilidade dos dados e o sucesso na seleção de genótipos superiores. Em todos as regiões, a produtividade de grãos apresentou relação $\mathrm{CVg} / \mathrm{CVe}$ superior a 1,00 e herdabilidade de 73,40, 73,50 e 68,86\% nas regiões Oeste, Sudeste e Central, respectivamente. A razão $\mathrm{CVg} / \mathrm{CVe}$, para produtividade de grãos e caracteres relacionados, superiores a 1,00 não tem sido encontrado em avaliação de progênies de meios-imãos de milho em Minas Gerais (SOUZA et al., 2009a).

A altura de planta e de espiga apresentou estimativas da relação $\mathrm{CVg} / \mathrm{CVe}$ superiores a 0,60 nas regiões Sudeste e Central e superiores a 0,90 na região Oeste. A prolificidade teve estimativas da relação CVg/ $\mathrm{CVe}$ e herdabilidade muito baixas, nas três regiões. As estimativas de herdabilidade para altura de planta e de espiga foram superiores a $52 \%$, nas três regiões de Minas Gerais, com exceção a altura de espiga na Região Oeste, onde a estimativa dessa foi de apenas $41 \%$. Assim, a maior parte da variação fenotípica apresentada por esses dois caracteres pela população de milho UFV 7 é de causa genética, na região Central e Sudeste de Minas Gerais. Desse modo, apenas para prolificidade não há expectativa de ganhos com a seleção de genótipos superiores.

As estimativas de correlação entre os caracteres, que não foram significativas a $5 \%$ de probabilidade pelo teste $\mathrm{t}$ ou método de bootstrap, não foram apresentadas (Tabela 3). Nas três regiões, os coeficientes de correlação genética aditiva $\left(r_{g}\right)$, fenotípica $\left(r_{p}\right)$ e ambiental $\left(r_{a}\right)$ significativa foram positivos. Além disso, a $r_{g}$ foi superior à $r_{p}$, sendo ambas maiores que a $r_{a}$, com exceção da $r_{g}$ entre prolificidade e altura de planta e espiga na região Central.

Na região Oeste de Minas Gerais, a $r_{g}$ entre produtividade de grãos, altura de plantas e de espigas foi de elevada magnitude. Desse modo, na população de milho UFV 7, grande parte dos genes envolvidos na expressão do caráter produtividade de grãos também está envolvida na determinação da altura de planta e de espiga. Assim, espera-se que a seleção de progênies superiores para produtividade de grãos seja eficiente em alterar a média de altura de planta e de espiga. Isso porque, além da $r_{g}$ entre esses caracteres se mostrar elevada, a herdabilidade para produtividade de grãos também é alta, o que evidencia eficiência de seleção direta para essa caráter e eficiência da seleção indireta para aumentar altura de planta e de espiga. É válido ressaltar que o ideal seria uma $r_{g}$ negativa entre produtividade de grãos e altura de planta e espiga, pois as cultivares de milho modernas tendem a apresentar altura de planta e de espiga inferior à obtida na população de milho UFV 7, na Região Oeste.
Na região Sudeste, a produtividade de grãos foi correlacionada apenas com a prolificidade. Como nessa região a estimativa de herdabilidade para esse caráter foi baixa, enquanto para produtividade de grãos foi alta, é possível obter ganhos indiretos em números de espigas por planta por meio da seleção direta de progênies mais produtivas. Entretanto, esse ganho é pequeno porque a prolificidade apresentou baixa variância genética nessa região. Em avaliação com população de milho crioulo no Sudeste de Minas Gerais, também não foi verificado $r_{g}$ entre produtividade de grãos e altura de plantas e de espigas (SOUZA et al., 2009b). Contudo, quando essa mesma população foi avaliada na região de Campos dos Goytacazes, houve $r_{g}$ entre produtividade de grãos e altura de plantas, embora negativa. Assim, a expressão dos alelos é influenciada pelo ambiente, de modo que a correlação entre dois caracteres pode ser alta em determinada região e, ao mesmo tempo, não haver correlação em outro ambiente para o mesmo germoplasma.

Na região Central, a produtividade de grãos foi correlacionada significativamente com todos os caracteres. Nessa região, foi observada $r_{g}$ de maior magnitude entre produtividade de grãos e prolificidade. Assim, espera-se que aumento na média da prolificidade com a seleção direta para produtividade de grãos. Quanto à altura de plantas e de espigas, a seleção direta para produtividade de grãos, caráter de maior estimativa de herdabilidade, proporcionará ganhos indiretos nestes. Isso é muito importante nessa população de milho, pois ela apresenta altura de planas e espigas inferior aos apresentados pelos cultivares modernos de milho, especialmente nessa região (SAWAZAKI \& PATERNIANI, 2004).

Nas três regiões edafoclimaticas de Minas Gerais, a $r_{g}$ foi positiva e de alta magnitude, entre altura de plantas e altura de espigas. Estas estão em concordância com estudos relatados na literatura para populações de milho (CHURATA \& AYALA-OSUNA, 1996; SOUZA et al., 2009b).

A correlação fenotípica $\left(r_{p}\right)$ é determinada por fatores genéticos e ambientais. Nesse trabalho, dispõe-se de estimativas de correlações genéticas aditivas. Portanto, o estudo de $r_{p}$ mostra-se ser de importância secundária. Ressalta-se, no entanto, que foram observadas elevadas estimativas de $r_{p}$ e $r_{a}$ entre altura de planta e espiga, nas três regiões. Assim, os caracteres em questão são influenciados pelas mesmas condições ambientais. Para os demais caracteres, os valores de $r_{p}$ e $r_{a}$ foram de baixa magnitude, ou seja, esses caracteres não foram afetados pelo ambiente.

As estimativas de parâmetros genéticos da população de milho UFV 7 mostram o potencial genético 
Tabela 3 - Estimativas e significâncias dos coeficientes de correlação fenotípica $\left(r_{p}\right)$, genética aditiva $\left(r_{g}\right)$ e ambiental $\left(r_{a}\right)$ entre os caracteres na população de milho UFV 7, nas três regiões de Minas Gerais.

\begin{tabular}{|c|c|c|c|c|}
\hline Região Oeste & & Altura de planta & Altura de espiga & Prolificidade \\
\hline \multirow{3}{*}{ Produtividade de grãos } & $r_{p}$ & $0,6260^{* *}$ & $0,5960^{* *}$ & $0,2849^{* *}$ \\
\hline & $r_{g}$ & $0,9176^{++}$ & $0,9408^{++}$ & ns \\
\hline & $r_{a}$ & $\mathrm{~ns}$ & ns & ns \\
\hline \multirow{4}{*}{ Altura de planta } & $r_{p}$ & & $0,8328 * *$ & ns \\
\hline & $r_{g}$ & & $1,0364^{++}$ & $\mathrm{ns}$ \\
\hline & $r_{a}$ & & $0,6389^{++}$ & $\mathrm{ns}$ \\
\hline & $r_{p}$ & & & ns \\
\hline \multirow[t]{2}{*}{ Altura de espiga } & $r_{g}$ & & & ns \\
\hline & $r_{a}$ & & & ns \\
\hline \multirow[t]{2}{*}{ Região Sudeste } & & Altura de planta & Altura de espiga & Prolificidade \\
\hline & $r_{p}$ & ns & ns & $0,4332^{* *}$ \\
\hline \multirow[t]{2}{*}{ Produtividade de grãos } & $r_{g}$ & $\mathrm{~ns}$ & ns & $0,5989^{+}$ \\
\hline & $r_{a}$ & $\mathrm{~ns}$ & $\mathrm{~ns}$ & $0,3282^{++}$ \\
\hline \multirow{3}{*}{ Altura de planta } & $r_{p}$ & & $0,8057^{* *}$ & ns \\
\hline & $r_{g}$ & & $0,9164^{++}$ & $\mathrm{ns}$ \\
\hline & $r_{a}$ & & $0,6740^{++}$ & ns \\
\hline \multirow{3}{*}{ Altura de espiga } & $r_{p}$ & & & ns \\
\hline & $r_{g}$ & & & ns \\
\hline & $r_{a}$ & & & ns \\
\hline \multirow[t]{2}{*}{ Região Central } & & Altura de planta & Altura de espiga & Prolificidade \\
\hline & $r_{p}$ & $0,6042^{* *}$ & $0,5753^{* *}$ & $0,6378^{* *}$ \\
\hline \multirow[t]{2}{*}{ Produtividade de grãos } & $r_{g}$ & $0,7122^{++}$ & $0,6633^{++}$ & $0,9142^{++}$ \\
\hline & $r_{a}$ & $0,4428^{++}$ & $0,4392^{++}$ & $0,3321^{+}$ \\
\hline \multirow{3}{*}{ Altura de planta } & $r_{p}$ & & $0,8707^{* *}$ & $0,3516^{* *}$ \\
\hline & $r_{g}$ & & $0,9435^{++}$ & ns \\
\hline & $r_{a}$ & & $0,7655^{++}$ & $0,3924^{++}$ \\
\hline \multirow{3}{*}{ Altura de espiga } & $r_{p}$ & & & $0,3313^{* *}$ \\
\hline & $r_{g}$ & & & ns \\
\hline & $r_{a}$ & & & $0,3801^{++}$ \\
\hline
\end{tabular}

*** Significativo a 1 e $5 \%$, pelo teste t, respectivamente.

${ }^{++},{ }^{+}$Significativo a 1 e $5 \%$, respectivamente, pelo método de bootstrap, com 5000 simulações.

ns não significativo a $5 \%$ de probabilidade, pelo teste t ou método de bootstrap.

dessa população a ser explorado com uso de distintas estratégias de melhoramento em diferentes regiões edafoclimáticas de Minas Gerais.

\section{CONCLUSÃO}

A população de milho UFV 7 apresenta potencial para extração de linhagens na região Central de Minas Gerais, para uso imediato na região Sudeste e para novos ciclos de seleção na região Oeste de Minas Gerais. A seleção para produtividade de grãos provoca aumento indireto na altura de plantas e altura de espigas, na população de milho UFV 7 , nas regiões Oeste e Central.

\section{REFERÊNCIAS}

BORÉM, A.; MIRANDA, G.V. Melhoramento de plantas. 5.ed. Viçosa: UFV, 2009. 529p.

Ciência Rural, v.40, n.6, jun, 2010. 
CARDOSO, M.J. et al. Melhoramento genético das cultivares de milho CMS 47 e BR 5039 (São Vicente) na região meionorte do Brasil. Revista Brasileira de Milho e Sorgo, v.2, p.88-96, 2003. Disponível em: <http://www.abms.org.br/revista/ revista_v2_n3/PDF/ARTIGO_08_milton.pdf $>$. Acesso em: 10 jun. $\overline{2} 009$.

CARVALHO, H.W.L. et al. Estimativas de parâmetros genéticos da variedade BR 5028-São Francisco no Nordeste brasileiro. Pesquisa Agropecuária Brasileira, v.38, p.929-935, 2003. Disponível em: <http://www.scielo.br/scielo.php?script=sci_pdf\&pid=S0100$204 X 2003000800005 \& \operatorname{lng}=\mathrm{pt} \& \mathrm{nrm}=\mathrm{iso} \& \mathrm{t} \operatorname{lng}=\mathrm{pt}>$. Acesso em: 5 jun. 2009. doi: 10.1590/ S0100-204X2003000800005.

CARVALHO, H.W.L.; SOUZA, E.M. Ciclos de seleção de progênies de meios-irmãos do milho BR 5011 Sertanejo. Pesquisa Agropecuária Brasileira, v.42, p.803-809, 2007. Disponível em: <http://www.scielo.br/scielo.php?script=sci_pdf\&pid=S0100$204 \times 2007000600006 \& \operatorname{lng}=\mathrm{pt} \& \mathrm{nrm}=\mathrm{iso} \& \operatorname{lng}=\mathrm{pt}>$. Acesso em: 6 jun. 2009. doi: 10.1590/S0100-204X2007000600006.

CHURATA, B.GM; AYALA-OSUNA, J.T. Correlações genotípica, fenotípica e de ambiente e análise de trilha em caracteres avaliados no composto de milho (Zea mays) arquitetura. Revista Ceres, v.43, p.628-636, 1996. Disponível em: <http://www.ceres.ufv.br/ CERES/revistas/V43N249P05096.pdf>. Acesso em: 10 jul. 2009.

CRUZ, C.D. et al. Modelos biométricos aplicados ao melhoramento genético. 3.ed. Viçosa: UFV, 2004. V.1, 480 p.

DEITOS, A. et al. Yield and combining ability of maize cultivar under different ecogeographic conditions. Crop Breeding and Applied Biotechnology, v.6, n.3, p.222-226, 2006. Disponível em: <http://www.sbmp.org.br/cbab/siscbab/uploads/ bd6ba09c-5395-d48d.pdf>. Acesso em: 10 ago. 2009.

IBGE. Instituto Brasileiro de Geografia e Estatística. Levantamento sistemático da produção agrícola.
Disponível em: < http://www.ibge.gov.br>. Acesso em: 25 jun. 2009.

MIRANDA, G.V. et al. Genetic variability and heterotic groups of Brazilian popcorn populations. Euphytica, v.162, p.431440, 2008. Disponível em: <http://www.springerlink.com / content/k912m750t0t17r1n/fulltext.pdf $>$. Acesso em: 10 ago. 2009. doi: 10.1007/s10681-007-9598-9.

MIRANDA, G.V. et al. Multivariate analyses of genotype $\mathrm{x}$ environment interaction of popcorn. Pesquisa Agropecuária Brasileira, v.44, p.45-50, 2009. Disponível em: <http:// www.scielo.br/scielo.php? script $=$ sci_pdf\&pid $=$ S 0100 204X2009000100007\&lng=pt \&nrm=iso\&tlng=en>. Acesso em: 20 set. 2009 . doi: 10.1590/ S0100-204X2009000100007.

PACHECO, C.A.P. et al. Interação genótipos x ambientes na avaliação de progênies de meios-irmãos de milho. Pesquisa Agropecuária Brasileira, v.33, p.433-439, 1998.

SAWAZAKI, E.; PATERNIANI, E. Evolução dos cultivares de milho no Brasil. In: GALVÃO, J.C.C., MIRANDA, G.V. (Ed.). Tecnologia de produção de milho. Viçosa: UFV, 2004. p.5683.

SILVA, R.G. et al. Potencial genético das populações de milho UFVM 100 e UFVM 200 avaliadas em solos com deficiência de nitrogênio. Caatinga, v.21, n.1, p.22-29, 2008. Disponível em: <http://periodicos.ufersa.edu.br/index.php/sistema/article/ viewFile/222/382>. Acesso em: 10 ago. 2009.

SOUZA, A.R.R. et al. Predicting genetic gain in the Brazilian white maize landrace. Ciência Rural, v.39, p.19-24, 2009a. Disponível em: <http://www.scielo.br/scielo.php?pid=S0103$84782009000100004 \&$ script $=$ sci_arttext\&tlng=en $>$. Acesso em: 10 ago. 2009. doi: 10.1590/S0103-84782009000100004.

SOUZA, A.R.R. et al. Correlação de caracteres de uma população crioula de milho para sistema tradicional de cultivo. Caatinga, v.21, n.4, p.183-190, 2009b. Disponível em: < http://periodicos.ufersa.edu.br/index.php/sistema/article/view/ 424/428>. Acesso em: 10 ago. 2009. 